\title{
Linguagem humana: produção de sentido na perspectiva da Semiótica Cognitiva
}

\author{
Juliane Ferraz Oliveira (CEFET/MG)* \\ https://orcid.org/0000-0003-1326-5609
}

\section{Resumo:}

Neste artigo, pretendo demonstrar a relação entre linguagem, cognição e experienciação sob a perspectiva da Semiótica Cognitiva, além de elencar alguns dos principais fundamentos dessa, relativamente nova, área de estudo. Com o intuito de ajudar pesquisadores que se interessem por esse campo de estudos, apresento, de forma sucinta, referencial teórico-metodológico visando auxiliar no desenvolvimento de pesquisas que tenham como objeto de análise o processo de produção de sentido em uma perspectiva cognitivista; atividades de linguagem humana; significação; processamento metafórico etc. Como este campo pressupõe estudos transdisciplinares, filio-me a pressupostos teóricos da Teoria da Enunciação a partir do princípio do dialogismo bakhtiniano; e, no campo da Semiótica Cognitiva, a pressupostos da Teoria da Arquitetura Mental e da Integração Conceptual brandtiana.

Palavras-chave: Linguagem. Produção de sentido. Semiótica Cognitiva. Cognição. Linguística Cognitiva.

\section{Abstract:}

\section{Human language: production of meaning from the perspective of Cognitive Semiotics}

In this article, I intend to demonstrate the relationship between language, cognition and experience from the perspective of Cognitive Semiotics, in addition to listing some of the main foundations of this relatively new area of study. In order to help researchers who are interested in this field of studies, I present in a succinct theoretical-methodological framework that can help the development of researches that has as object of analysis the process of producing meaning in a cognitive perspective; human language activities; significance; metaphorical processing, etc. As this field presupposes transdisciplinary studies, I join the theoretical assumptions of the Enunciation Theory from the principle of Bakhtinian dialogism; and, in the field of Cognitive Semiotics, the assumptions of Theory of Mental Architecture and Conceptual Integration of Brandt.

Keywords: Language. Production of meaning. Cognitive semiotics. Cognition. Cognitive Linguistics.

* Professora do CEFET/MG. Doutoranda do Programa de Pós-Graduação em Letras da Puc Minas. Bolsista Capes II. E-mail: julianeferraz@cefetmg.br/ jujuh.ferraz@hotmail.com. 


\section{Uma perspectiva cognitivista da linguagem}

A tentativa de compreender a linguagem como intrínseca à natureza dos seres humanos sem, para isso, dissociá-la das práticas sociais é o fundamento sobre o qual se ancora este artigo. Firmando-me em princípios teóricos identificados no âmbito da Semiótica Cognitiva, adoto uma concepção de linguagem como forma de acesso a habilidades e processos cognitivos. Nesse sentido, a linguagem aqui passa a ser compreendida como um sistema sociocognitivo por meio do qual, nós seres humanos, construímos "cenas" no processo de interação que efetivamente fazemos para viver.

A linguagem, como um sistema natural aos seres humanos, se constitui, para significar o mundo e a si, por meio das relações biossociais e ambientais, integrando o sistema cognitivo humano, sendo imprescindível no processo de auto-organização da nossa espécie. Assim, a linguagem é indispensável para a organização social estabelecida pelos laços comunicativos, edificados no decorrer da construção da vida em comunidade, e para a criação de domínios abstratos (política, economia, justiça, entre inúmeros outros) que constituem o mundo da vida ${ }^{1}$. (BRANDT, 2004).

Em outras palavras, essa abordagem humana da linguagem privilegia desde a organização social, o nicho de vivência do ser, suas funções biocognitivas, até os sistemas

1 Conceito filosófico identificado no campo da fenomenologia, em especial, nas obras de Hussell (1859-1938) e Habermas (1929). Em uma perspectiva fenomenológica, neste trabalho, o conceito pode ser compreendido como a construção do mundo pelo ser humano. 0 que implica habilidades cognitivas básicas como: percepção, atenção e memória; e operações mentais constitutivas básicas: integração conceptual, categorização, perspectivação, dentre outras. abstratos deles derivados e fundadores. Uma perspectiva sistêmica da linguagem permite-nos compreendê-la como propiciadora da vida no mundo. Por meio de nossas significações e funções sensoriais, via nossas funções cognitivas e motoras, e de fenômenos abstratos e complexos, somos capazes de criar e experienciar o mundo. Desta maneira, é possível investigar uma gama de objetos que estão implicados nas práticas discursivas e multimodais humanas. (BRANDT, 2004).

Essa é uma perspectiva plausível, coerente, com um objeto de análise amplamente discutido no âmbito das pesquisas em linguagem, o processamento metafórico. Já que não é preciso, nem possível, dissociar o ser humano de suas práticas sociais ou do meio que co-constrói, pode-se afirmar que o processo metafórico está implicado na experiência humana, em práticas discursivas mono ou multimodais.

Princípios cognitivistas deixam vir à tona o pensamento de que a linguagem é o elo principal entre a comunicação e a cognição em nossa espécie. Isso propicia o compartilhamento de parte significativa do pensamento dos seres humanos entre si que nomeamos como cultura, civilização e humanidade. (BRANDT, 2009).

Nós, seres humanos, criamos e atualizamos, ao longo de centenas de anos, sistemas e tecnologias de produção de significados e comunicação. Assim, a linguagem, por ser nosso principal sistema de significação, constitui uma complexa ligação entre a comunicação e a cognição, possibilitando-nos a vida em comunidade. Observemos a citação a seguir, em que Brandt (2009) defende essa perspectiva teórica:

É preciso uma interpretação linguística dos nossos signos para transmitir socialmente seus significados: as ocorrências de varia- 
ções em nossa interpretação linguística de expressões não linguísticas, nossas e dos outros, podem explicar o caráter dinâmico e criativo do pensamento/ e da comunicação - e consequentemente certos aspectos da história das ideias. ${ }^{2}$ (BRANDT, 2009, p. 3, tradução livre).

Somos seres de linguagem e, portanto, só concebemos a vida, tal como ela é, por meio dos usos que fazemos da linguagem para viver. Nossa atividade no mundo, como seres produtores de significados, só é possível por conta do compartilhamento de habilidades cognitivas como a percepção, a atenção, a memória e por nossa capacidade de produzir e compartilhar sentidos simbolicamente. A linguagem humana é uma atividade simbólica, natural, sistêmica, complexa, através da qual produzimos sentido.

Adotar essa perspectiva cognitivista nos leva a compreender o ser humano como ímpar/particular por este estabelecer relações com os outros seres que não ele mesmo, a interação humana com seus co-específicos é uma característica constitutiva da espécie. Desta maneira compreendida, o ser humano é um ser biossocial, que precisa ser investigado como um ser considerado imerso em seu contexto de vivência, e, portanto, fundamentalmente implicado na constituição do meio e do outro. Por outro lado, compreender a linguagem e a cognição, em uma perspectiva corporificada, assegura que a mente e a organização conceptual, maneira como significamos o mundo, o outro e a vida, resultam de como nosso corpo interage com o meio em que vivemos. (CAVALCANTE \& SOUZA, 2010).

2 It takes a linguistic interpretation of our signs to socially transmit their meaning; the variations occurring in our linguistic interpretation of our own and each other's non-linguistic expressions may even explain the dynamic and creative character of thoughtful communication - and hence certain aspects of the history of ideas.
Em um contexto estruturado pelas relações sociais, nos tornamos sujeitos no momento em que nos relacionamos com os outros. Só existe um eu quando relacionado a um tu. (VOLOCHINOV, 2018). A existência, a individualidade humana é marcada pelo que não se é, ou seja, o outro. Em uma perspectiva convergente, podemos afirmar que: "[...] ser significa comunicar-se, e um eu é alguém que, por sua vez, é um tu para outro." (ZAVALA, 2009, p. 153).

De acordo com essa concepção de linguagem, de natureza cognitivo-social, o pensamento metafórico é uma capacidade mental indissociável de quaisquer atividades mentais, mesmo as ordinárias, dos seres humanos. Assim, a produção metafórica aqui compreendida não é a simples figura de linguagem, como proposto nos manuais de ensino.

A teoria da Integração Conceptual, também originalmente reconhecida como Conceptual Blending, assume lugar de importância diante desses princípios. A operação mental básica, blend, permite que a atividade humana de pensamento possua um grau altamente imaginativo, criativo e metafórico, que é imprescindível para originar qualquer tipo de significação, por mais simples que essa seja. A assunção do pensamento e da linguagem como metafóricos não significa compreender a si no mundo por meio de tropos linguísticos ou parábolas lexicais. Significa, antes disso, a capacidade, extremamente complexa, criativa e comum, que temos de construir uma atividade inconsciente, invisível e intermitente envolvida em todos os aspectos da vida humana. Em consonância com essa perspectiva, podemos afirmar que fazemos blends para viver. (FAUCONNIER \& TURNER, 2002).

$O$ pensamento metafórico humano, a capacidade de integrar espaços input para 
criar novos espaços blend, possibilita o processamento metafórico da linguagem. No âmbito desse enquadramento teórico, fica claro que, cognitivamente, projetamos e operamos com esquemas aprendidos e apreendidos pelo corpo para (inter)agir com e no mundo. 0 pensamento é, por natureza, criativo, ainda que comum/ordinário, e essa característica não é algo que seja restrito aos "gênios". (FAUCONNIER \& TURNER, 2002).

Falar em pensamento criativo-metafórico, como algo que ocorre de maneira rotineira na vida de todo ser humano, pode causar estranheza, mas, compreender que a mente humana trabalha de maneira incessante na atualização de significações novas, ou parcialmente novas que derivam de estímulos já conhecidos, ou nunca antes pensados, pode explicar parte desse processo. Sobre isso, Fauconnier \& Turner (2002) afirmam que:

O pensamento metafórico, tido do ponto de vista do senso comum como um instrumento especial da arte e da retórica, opera em níveis da cognição e mostra uniformidade estrutural e princípios dinâmicos, independentemente se isso é especial e noticiável ou convencional e normal. ${ }^{3}$ (FAUCONNIER \& TURNER, 2002, p. 17, tradução livre).

Essa abordagem da atividade humana, como biossocial e cultural, permite-nos compreender a linguagem humana como algo que extrapola os limites da mera formalização, e nos leva a tentar propor uma explicação mais cognitivamente plausível de fatos linguísticos e de fenômenos discursivos. (TAYLOR apud: CAVALCANTE \& SOUZA,

3 Metaphoric thinking, regarded in the commonsense view as a special instrument of art and rhetoric, operates at every level of cognition and shows uniform structural and dynamic principles, regardless of whether it is spectacular and noticeable or conventional and unremarkable.
2010). Isso nos permite investigar o fenômeno linguístico-cognitivo da produção de metáforas de maneira integrada, em todas as manifestações orgânicas do corpo do ser humano.

Ainda que seja curioso,

[...] a sistematicidade e a complexidade de algumas de nossas mais básicas e comuns habilidades mentais não foram reconhecidas por tanto tempo. Talvez a forma desses mecanismos importantes na vida os faça invisíveis para a consciência. ${ }^{4}$ (FAUCONNIER \& TURNER, 2002, p. 18, tradução livre).

Por não ser um fenômeno facilmente observável, os estudos que priorizam a vertente cognitiva da linguagem integram uma corrente, de certo modo, recente de possibilidades investigativas, o que torna o desenvolvimento deste artigo ainda mais desafiador. Na próxima seção, discutirei outro princípio constitutivo da linguagem, e assim, da própria vida, caro aos fundamentos teóricos deste artigo, o princípio dialógico.

\section{A dialogicidade: um princípio constitutivo da linguagem}

Na escrita desse artigo, parto do princípio de que os discursos construídos e construtores em/de um meio social pelos seres humanos são, sempre e necessariamente, novos. Essa concepção me impele a pensar que, ainda que não sejam inaugurais, na atividade de linguagem, esses discursos constituem novos olhares e novas formas de conceber o meio sociocultural e as relações sociais, através da nossa concepção do mundo e do outro. Assim, ao interagirmos discursivamente com o outro, e o fazemos

$4 \quad[\ldots]$ the systematicity and intricacy of some of our most basic and common mental abilities could go unrecognized for so long. Perhaps the forming of these important mechanisms early in life makes them invisible to consciousness. 
em diferentes e concretas situações da vida, reiteramos, no processamento discursivo, marcas históricas e sociais que nos caracterizam em uma dada cultura e uma dada sociedade, em um dado espaço e tempo.

0 dialogismo não se restringe à ideia de um diálogo que possa ser estabelecido face a face entre os interlocutores, mas está fundamentalmente implicado nas relações firmadas entre os mais variados discursos. Volochínov (2018) afirma a esse respeito que a palavra é um ato bilateral. Para este autor, toda palavra comporta duas faces: ela é determinada tanto por aquele de quem ela procede quanto por aquele para quem se dirige.

0 círculo bakhtiniano propunha uma visão de discurso que engloba homem e vida, compreendendo a faceta social do ser como o principal marcador das possibilidades discursivas existentes. Nessa perspectiva, o discurso não pode ser tomado como acontecimento unicamente individual porque se constrói entre dois interlocutores, ou mais, que se relacionam socialmente. Assim, a construção de uma rede de contato entre os vários discursos estabelece relações com discursos precedentes e derivados. (MARCUZZO, 2008).

Compreender o ser humano como um ser intrinsecamente social é premissa básica a partir da qual se reconhece o caráter dialógico da linguagem humana. O Outro se faz imprescindível para a concepção do $E u$ discursivo e social. Nessa perspectiva, portanto, é impensável conceber o homem fora de suas relações com o outro e com o meio. Essa concepção, também, é a adotada em uma perspectiva cognitivista da linguagem como, simultaneamente, biológica, social e cultural.

Só construímos significados, como seres sociais que somos na alteridade. A atividade responsiva possibilita que a dialogicida- de seja identificável. 0 reconhecimento de marcas que nos ajudam a identificar vestígios contextuais, históricos e culturais no discurso, reveladores do princípio do dialogismo, tornam plausíveis estudos que adotem esses fundamentos. 0 dialogismo converge para uma perspectiva cognitivista da linguagem à medida que, nessa perspectiva, o ser humano está no cerne da investigação científica.

Na perspectiva do círculo bakhtiniano, o diálogo é uma reação do eu ao outro, ou seja, a reação da minha palavra à palavra que emana de outrem, constituindo-se como ponto de tensão entre o eu e o outro. Este estabelece, nessa relação, círculos de valores que possibilitam a constituição de uma comunidade de comunicação, que pressupõe uma tensão entre forças sociais por meio das relações de poder instauradas no corpo do grupo de vivência do indivíduo, como um ser social. (MARCHEZAN apud BRAIT, 2010).

Nesse sentido, comunicar é produzir sentido sempre a dois, no mínimo. As práticas enunciativas pressupõem a interação como aspecto constitutivo da atividade de linguagem humana. Frente a esses fundamentos, pelo reconhecimento do princípio da alteridade, da dialogicidade da linguagem e da própria cognição humana, não interessa investigar a palavra unicamente, mas a palavra em uso, que possibilita a construção de contextos de atuação complexos e heterogêneos dos sujeitos sociais, vinculados a situações e a falas passadas e antecipadas. Isso significa reconhecer, em consonância com Volochínov (2018), que o objeto a ser investigado vai ao encontro da abordagem dialógica da linguagem.

A significação não está na palavra nem na alma do falante, assim como também não está na alma do interlocutor. Ela é o efeito da 
interação do locutor e do receptor produzido através do material de um determinado complexo sonoro. (VOLOCHINOV, 2018, p. 232).

Todo discurso é fruto de um discurso anterior e prévio de um discurso futuro, constituindo, assim, aspectos de um fio condutor de uma comunicação ininterrupta e solidificada. 0 que pressupõe o decurso histórico do qual o indivíduo é construtor e construto. A dialogicidade da linguagem possibilita a identificação de ecos, de discursos anteriores, em diferentes práticas enunciativas. (VOLOCHINOV, 2018).

Pelos argumentos apresentados até este momento, é possível perceber que entre os fundamentos adotados, para a realização de futuros trabalhos de pesquisa e análise que adotem a perspectiva de linguagem sistêmica, encontram-se: i) os seres humanos criam o mundo a partir de capacidades cognitivas gerais e discursivo-cognitivas especificamente; ii) essas capacidades cognitivas estão fundamentalmente implicadas na atividade de linguagem; iii) a atividade humana a que denominamos linguagem configurase como um sistema sociocognitivo natural e complexo; iv) essa atividade pressupõe que a espécie humana age e produz sentido dialogicamente; v) o princípio dialógico da linguagem e, portanto, da produção de sentido está na base das relações biossociais e culturais da espécie humana.

Tendo em vista o exposto, na próxima seção, apresento princípios teóricos que podem sustentar estudos que tenham como foco relação entre linguagem e cognição.

\section{A semiótica cognitiva}

Esse artigo baseia-se, fundamentalmente, em pressupostos teóricos e metodológicos inscritos na Semiótica Cognitiva desenvolvida pela Universidade de Aarhus e, mais especificamente, ancorada em trabalhos desenvolvidos por Brandt (2004; 2010) e Zlatev (2012).

Ao tentar identificar, apreender e analisar o processo de produção de sentido sob a ótica dos estudos cognitivos, em particular do processo de metaforização, em uma perspectiva gestáltica (biofisiológica, sociocultural e política), encontrei na Semiótica Cognitiva terreno fértil para desenvolver minha investigação. A Semiótica Cognitiva (SC) caracteriza-se por ser um campo de estudo que se dedica à compreensão da produção de sentido pelo ser humano em seu contexto de constituição do mundo. (BRANDT, 2004).

Nesse sentido, é um amplo campo de investigação transdisciplinar, assim intitulado por não constituir um domínio empírico e teórico único e específico, tendo como foco principal o fenômeno plural da significação. A transdisciplina SC é proposta com o intuito de preencher lacunas históricas abertas pelos modelos de pesquisa tradicionais, que privilegiam uma metodologia de investigação que desvincula as áreas do conhecimento, além de reificar os objetos de pesquisa, fazendo com que haja o seccionamento dos trabalhos em grades disciplinares que, frequentemente, não se relacionam entre si. (ZLATEV, 2012).

Esses moldes tradicionais de pesquisa foram forjados sobre princípios que levaram muitos pesquisadores a acreditar que o particionamento do ensino facilitaria a aprendizagem. Isso fez com que organizássemos as possibilidades de análise em campos de conhecimento supridos, durante muito tempo, por bases teóricas construídas a partir do afastamento do ser humano do centro das investigações. Nesse contexto, a Semiótica Cognitiva indica uma nova possibilidade de investigação ao propor uma "desfragmentação" de disciplinas, como psicologia e 
linguística, para que, dessa maneira, não sejam vistas como áreas conflitantes e, então, comecemos a compreender as produções humanas em termos biológicos, mentais e socioculturais conjuntamente.

Desenvolver um trabalho fincado nessa matriz interdisciplinar é assumir o desafio de explorar uma área de trabalho que coloca sempre o ser humano, a partir de uma perspectiva filogenética e evolucionista, no cerne do processo investigativo da produção de sentido por meio da linguagem, implicado na experiência humana, em práticas de encenação discursiva mono e multimodais.

Um exemplo de possibilidade investigativa encontra-se na dissertação "O cômico na Era Digital: um estudo sobre o processo de metaforização implicado na experiência humana do riso", de minha autoria. Nele, o processo de metaforização, como estratégia discursiva constitutiva da encenação cômica, é estudado a partir de uma perspectiva que privilegia as formas humanas de construção de significado, por meio da linguagem multimodal. Dentre os fatores de linguagem determinantes na constituição do cômico, no âmbito da cultural digital, explicito a instauração de cenas enunciativas, que pressupõem a instanciação de uma relação eu-tu no compartilhamento atencional para um determinado elemento referencial, compreendendo esse fator como constitutivo da produção de sentido, como um todo, adotando o princípio de compartilhamento de atenção como axiomático no processo de significação diante de cenas humorísticas.

0 trabalho explicitado acima é um dos muitos que tem o intuito de compreender os processos de comunicação, de interação da mente humana, ancorado na SC, que propõe analisar a arquitetura geradora de significado da mente humana e da consciência: a cognição.
Fundamentar uma pesquisa nos princípios teóricos e parâmetros de análise da Semiótica Cognitiva significa desvincularse de uma perspectiva puramente social ou puramente biológica e conceber o mundo e todas as manifestações da vida cotidiana como co-construções, feitas por nós seres humanos, através de nossas percepções e ações. Os objetivos desse, relativamente, novo campo do saber, podem parecer audaciosos, e realmente o são, ainda mais se pensarmos na mudança radical da ótica investigativa na qual colocamos o ser humano, de fato, como construtor do mundo.

Adotar essa concepção de análise faz com que o pesquisador abra mão da noção de significado como algo a ser compreendido "fora" do indivíduo, fazendo-o priorizar aquilo que é mais básico no processo de significação, na produção de qualquer significado: o ser humano. Nesse cenário, a experiência fenomenológica passa a ser um dos princípios fundadores dos procedimentos metodológicos de trabalhos nessa área. É possível, então, compreender que no campo do conhecimento aqui descrito, a experiência do ser humano, nos processos de interação que estabelece com o outro, no mundo da vida, é o principal elemento a ser analisado.

Assim, torna-se coerente propor análises de manifestações linguístico, gestuais, imagéticas e sonoras constitutivas do processo de encenação discursiva em que as manifestações de linguagem se estruturam. Então, é plausível adotar uma perspectiva multimodal de comunicação. Essa opção pode conduzir à criação de caminhos para a análise de variados objetos e para as verificações de hipóteses, que incluem a necessidade de refletir sobre o funcionamento biológico, sociocultural e político do ser humano.

Para compreender o fenômeno da significação, propomos a adoção do pensamen- 
to brandtiano de que conteúdos mentais são organizados numa integração de "materiais" de níveis baixos e altos levando em consideração aspectos biofisiológicos e socioculturais do ser. 0 que não significa dizer que há um movimento hierárquico na integração desses "materiais"5. (BRANDT, 2010).

\section{- Níveis de integração - ligações de conteúdos mentais}

De acordo com Brandt (2010), a arquitetura mental da significação pode ser compreendida como uma maneira de mapear os possíveis estágios da significação nas mais diferentes construções contextuais humanas possíveis. 0 pesquisador demonstranos, de maneira didática, como o processo de produção de sentido é composto por dimensões centrais e periféricas (em relação ao corpo) da biofisiologia humana, deixando claro que, ao nos privarmos de algum desses aspectos da produção de significado, estaremos negando os princípios da própria significação.

A proposta de Brandt (2010), ao descrever essa arquitetura mental, é explicar de que maneira significamos. Para isso, propõe uma organização em níveis de compreensão e constituição do mundo pelo ser humano. $\mathrm{O}$ autor os divide em cinco, do nível I ao $\mathrm{V}$, que vão desde os qualia, passando pelos níveis intermediários compostos por eventos, situações e contextos, correspondendo aos níveis de II a IV, respectivamente, e pela experiência afetiva como o nível V.

As formas mais básicas identificadas no processo de integração são denominadas qualia. Essas são formas monomodais. Geralmente, os qualia estão em primeiro pla-

5 De acordo com BRANDT (2010), "materiais" mentais é o que percebemos e integramos no mundo feno-físico. no, como qualia estéticos, ou absorvidos em entidades de ordem superior, formas multimodais. As cores, linhas, sons e formas são identificáveis pelo sistema sensório -perceptual humano e representam formas desintegradas de integrações prévias, ou manifestadas sem qualquer outra integração, contextual, situacional ou de coisas. É o primeiro contato humano, mais fisiologicamente dependente e menos culturalmente variável, com qualquer forma no mundo. (BRANDT, 2010).

A respeito dos níveis de integração, o pesquisador afirma que:

O núcleo da consciência humana - níveis II, III e IV - é culturalmente variável quanto ao seu conteúdo atual. Eles não são variáveis quanto aos tipos de integração que os articula, mas, certamente se levarmos em consideração os objetos atuais, situações e formas de conhecimento que eles contêm. ${ }^{6}$ (BRANDT, 2010, p. 28, tradução livre).

Em sua proposição teórica, fica claro que os níveis periféricos são mais fisiologicamente dependentes e menos culturalmente variáveis, enquanto os três níveis intermediários têm como características serem criações culturais e "abrigarem" o núcleo da consciência humana. Isso não significa que os níveis intermediários sejam variáveis quanto aos tipos de integração que os articulam, mas, sim, em relação ao seu conteúdo atual.

A disposição dos níveis da arquitetura mental não representa uma forma enrijecida sequencial de ordem crescente ou decrescente do processo de significação. 0 diagrama abaixo nos permite observar como

6 The central core of human consciousness - levels II, III, and IV - are thus culturally variable as to their actual content. They are not variable as to the sorts of integration that articulates them but certainly regarding the actual objects, situations, and knowledge forms that they contain. 
Brandt (2010) compreende os níveis anteriormente descritos e, ainda, a forma como esses se integram, no processo de significação humana.

Figura (1): Diagrama da integração em níveis.

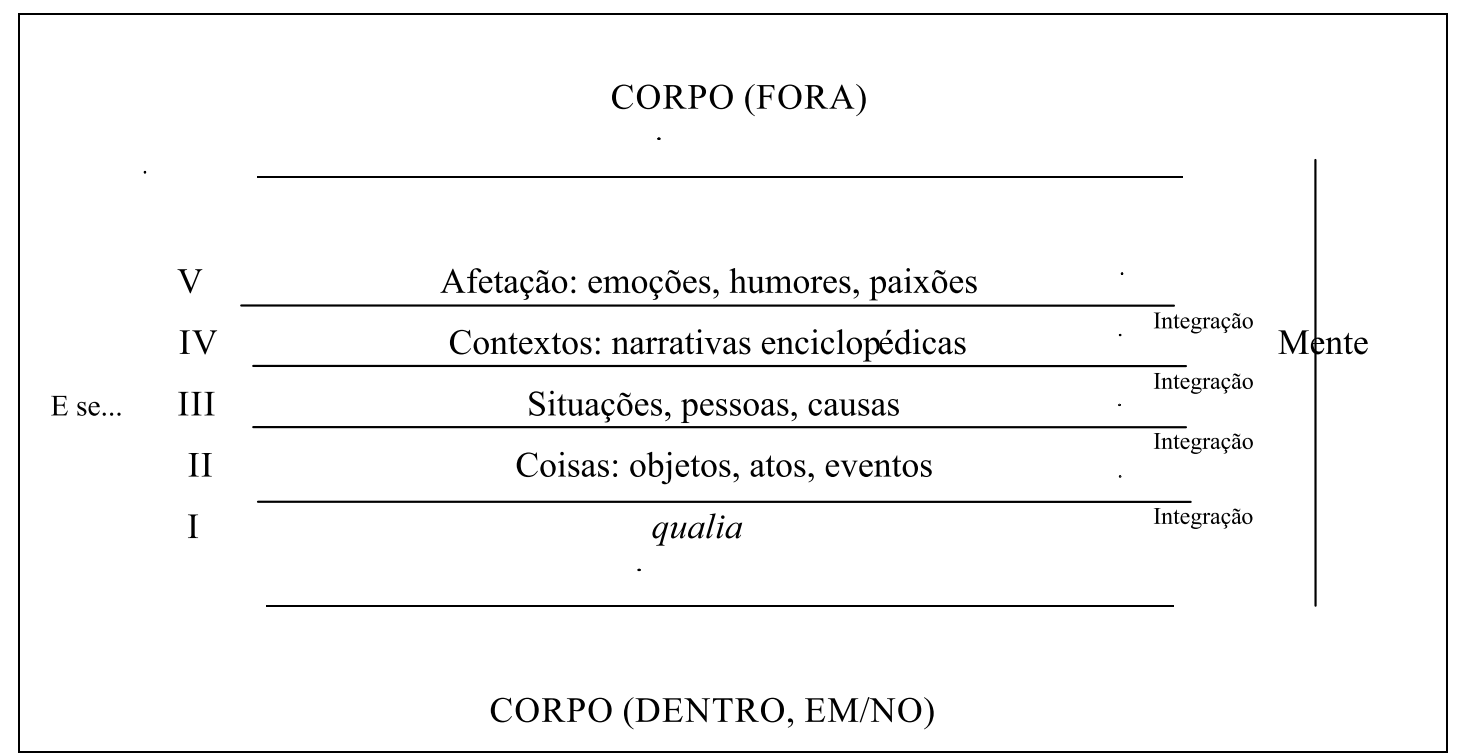

Fonte: Adaptado pela autora. (BRANDT, 2010, p.27).

Na perspectiva ora descrita, a produção de sentido acontece a partir de processos integrativos, em todas as direções, que permitem retroprocessos, o que faz com que sejam possíveis integrações e desintegrações em diversas direções, para cima e para baixo, além das transversais, que não precisam perpassar todas as camadas da arquitetura.

De acordo com o pesquisador, a arquitetura mental nos leva a compreender que a linguagem possibilita que nos refiramos a certos qualia e experiências afetivas. Isso acontece de forma grosseira, já que, para operar nesses níveis, I e V, recorremos ao uso intenso de metáforas, pois, a linguagem de nossa espécie só permite que ajamos de forma mais "literal" em níveis que operamos a cultura, II a IV. (BRANDT, 2010).

Enquanto o autor configura qualia (I) como formas monomodais, as experiências afetivas (V) perpassam significações multimodais. Os qualia e as reações afetivas têm em comum o fato de poderem sofrer influência cultural muito menor que outros níveis da arquitetura. Assim, podemos ob- servar a pouca variabilidade quanto a essas sensações e sentimentos configurados como de níveis I e $\mathrm{V}$, ainda que possam ser vivenciados e significados de maneiras diferentes em cada lugar, a depender da simbolização cultural atribuída a esses sentimentos e sensações. Um sorriso será sempre um sorriso, ainda que seja fruto de produções culturais diferentes.

Há ainda a possibilidade de vivenciar algo que Brandt (2010) nomeia como experiência estética, que seria uma capacidade humana de ir do nível I ao $\mathrm{V}$ sem que seja preciso passar pelos níveis de II a IV. Isso significa que nós humanos, através da arte, temos a capacidade de experienciar qualia estéticos no âmbito das manifestações afetivas, por meio da integração de materiais de níveis não adjacentes. Desta forma, experienciar a arte seria a única maneira de transcender as restrições culturais na significação, na comunicação e no pensamento. (BRANDT, 2010).

Por isso, compreendo como preponderantes, para estudos acerca do processo de 
significação, numa perspectiva holística, integrando ciências humanas, biológica e mesmo exatas, tanto os aspectos biofisiológicos do ser, quanto os aspectos sociais, culturais e políticos da sua existência e formas de (inter)ação no mundo. Assim, o processo investigativo será, antes de mais nada, pesquisa sobre o ser humano, seu meio e suas ações.

A seguir, com o intuito de aprofundar a explicitação de fundamentos que podem permitir pesquisas sobre o processo de significação humana por meio da linguagem, apresento os fundamentos implicados na compreensão do processo de integração conceptual, uma operação cognitiva básica constitutiva do processo de produção de sentido, pelo ser humano.

\section{- Integração conceptual: operação cognitiva básica no processo humano de significação}

A Semiótica Cognitiva, campo do conhecimento em que se inscrevem os principais fundamentos teóricos deste trabalho, tem como uma de suas premissas a assunção de que, ao produzir sentidos, instauramos e integramos espaços mentais e que essa é uma operação cognitiva básica realizada pelo ser humano no ato de significação.

A definição de espaços mentais aqui adotada vai ao encontro daquela proposta pelos pesquisadores da Universidade de Aarhus. Esses pesquisadores compreendem espaços mentais como "[...] minidramas dinâmicos que contam com recursos esquemáticos de interatividade." (OAKLEY; HOUGAARD, 2008, p. 85). Nessa perspectiva, os espaços mentais organizam-se em termos da criação de cenas integradas a outras cenas que formam uma cena integrada com características ontológicas únicas.
Coulson \& Oakley (2008), por sua vez, definem espaços mentais:

[...] como representações de cenas e situações em um dado cenário discursivo então percebido, imaginado, relembrado e por outro lado entendido por um falante. Espaços mentais são usados para empacotar informações de interesse de um interlocutor de dentro de um contexto interativo. ${ }^{7}$ (COULSON; OAKLEY, 2008, p. 29, tradução livre).

Como é possível observar, tal definição leva em conta tanto aspectos biofisiológicos envolvidos na operação cognitiva de blending (integração conceptual) quanto às cenas formadas de maneira introspectiva e as situações socioculturais por elas envolvidas.

O blending proposto como operação cognitiva básica amplamente aplicável, naturalmente efetuada pelo ser humano, atua como uma parte significativa de muitos fenômenos cognitivos, o que pode ser "flagrado" em experiências humanas como design, ciência, linguagem, arte, e assim por diante. Os pesquisadores afirmam que essa operação é efetuada a todo momento, inconscientemente, pelo nosso organismo para que possamos interagir com o meio que nos cerca e com o outro, de maneira efetiva e satisfatória. (FAUCONNIER \& TURNER, 2002).

Segundo a tese defendida por Fauconnier \& Turner (2002), na Teoria da Integração Conceptual ${ }^{8}$, por esta operação ser realizada de maneira invisível para a nossa

$7 \quad[. .$.$] we define mental spaces as representations$ of the scenes and situations in a given discourse scenario as perceived, imagined, remembered or otherwise understood by the speaker. Mental spaces are used to package information about an interlocutor's center of interest within an interactive context.

8 É preciso ressaltar que a Teoria da Integração Conceitual é aqui retratada como forma de revelar aspectos da integração que na teoria brandtiana não estão claramente descritos, por serem axiomáticos. 
consciência, por muito tempo, acreditamos que os significados se encontravam, de alguma forma, acessíveis no mundo fora do indivíduo. Isso fez com que, por um longo tempo, não levássemos em conta que, cognitivamente, os significados são construídos de maneira interativa e, também, não tivéssemos consciência de que o que existe não são as coisas do/no mundo para que sejam por nós apreendidas e mensuradas. Na realidade, construímo-nos no mundo e construímos o mundo em que vivemos $\mathrm{e}(\mathrm{m})$ suas possíveis significações a partir da interação (eu-tu) lastreada pelo aspecto cognitivo de um organismo que age no mundo.

Frente a essa proposição teórica, o que se tornou cada vez mais claro é que não há busca de compreensão que não a do próprio ser. Não há construção de significados que não perpasse um processo mental de percepção do ser em sua relação com o outro e com o mundo, e nada disso seria possível em um ser humano que fosse concebido isolado do seu contexto social.

Sobre os supracitados aspectos cognoscitivos da vida como uma manifestação cognitiva dos humanos, Fauconnier \& Turner (2002) afirmam que:

Após um blend ter sido construído, as correspondências - as identidades, as similaridades, as analogias - parecem ser objetivamente parte do que estamos considerando, e não alguma coisa que nós tivemos de construir mentalmente. Como quando nós achamos que vemos um copo de café pela simples razão de que lá existe um copo de café para ser visto, então achamos que vemos a analogia porque lá existe uma analogia para ser vista - que é para ser percebida direta e imediatamente sem nenhum esforço. ${ }^{9}$ (FAU-

9 After a blend has been constructed, the correspondences - the identities, the similarities, the analogies - seem to be objectively part of what we are considering, not something we have constructed mentally. Just as we feel that we see
CONNIER \& TURNER, 2002, p. 19, tradução livre).

A tarefa, de certa maneira fácil e involuntária, de se construir um blend, instantaneamente e em tempo real, demanda um dispêndio cognitivo que não conseguimos mensurar. A construção de blends exige habilidades de executar cenários em unidades integradas, ainda que isso não tenha correspondência com nenhuma realidade ou experiência previamente imaginada/vivenciada. Assim, as dinâmicas desse cenário imaginativo são executadas de forma automática pelo organismo, ainda que nunca tenham sido executadas antes. (FAUCONNIER \& TURNER, 2002).

A operação de blending torna possível uma série de combinações que parecem óbvias para nós, mesmo que nunca as tenhamos combinado antes. Essas combinações, que efetuamos por meio da integração de espaços mentais, nos ajudam a executar esse blend e esta execução nos permite encontrar mais combinações, o que torna a rede de integração ininterrupta e mutuamente dependente. (FAUCONNIER \& TURNER, 2002).

Desta maneira, a integração de espaços mentais é recursiva e indispensável para toda atividade intelectual. 0 que não garante uma uniformidade das execuções possíveis de serem estabelecidas pelos blends, já que esses podem ocorrer de diversas maneiras para um mesmo indivíduo e, também, de maneiras variadas para diferentes indivíduos. Os blends são estabelecidos tanto no que tange aos aspectos fantásticos e criativos da cognição como nos raciocínios construídos no uso ordinário, cotidiano, acontecendo em todas as situações. Assim

the coffee cup for the simple reason that there is a cup to be seen, so we feel that we see the analogy because there is an analogy to be seen - that is, to be perceived directly and immediately with no effort. 
compreendidos, podemos afirmar que a integração de espaços mentais, na forma de integrações conceptuais (blends), compõe tanto a atividade intelectual quanto os padrões cotidianos de ações corporais. Nessa perspectiva, os blends não dizem respeito apenas ao nosso trabalho, exclusivamente, mental, mas ao nosso estar e agir no mundo. (FAUCONNIER \& TURNER, 2002).

Os pesquisadores reconhecem que o cérebro é um órgão altamente conectado com o organismo e interconectado em si mesmo, e que as ativações dessas conexões pelos neurônios surgem das forças que o mundo real impinge sobre nós. Essas forças são advindas de pessoas que falem conosco, de nossas suposições, de configurações internas, ou mesmo da cultura e da evolução biológica, aquilo que permanece em nós por herança genética de nossos ancestrais.

Muitos podem ser os gatilhos para o desencadeamento de padrões de ativações neurais que executem blends de significação. Como podemos constatar a seguir, os autores afirmam que as palavras contribuem para o processo de integração: "As palavras são, por si mesmas, parte de padrões de ativação, assim, quando a mesma palavra é apropriada para dois elementos, podemos induzir alguém a associá-los ao usar a mesma palavra para ambos."10 (FAUCONNIER \& TURNER, 2002, p. 22, tradução livre).

Por mais simples que pareça ser uma construção linguística, ela depende de um blend complexo. Os blends podem ser infinitos, ainda que se originem dos mesmos inputs, e que o processo seja o mesmo, a integração conceptual, o resultado é diferente. Somos seres cognitivos por essência, então o

10 "Words themselves are part of activation patterns, so when the same word is appropriate for two elements, we can prompt someone to match them by using the same word for both." blend, que executamos mentalmente, transforma imaginativamente as nossas realidades humanas mais fundamentais. Os significados que construímos têm grande importância, tanto no modo como damos relevância ao individual, quanto ao social, e mesmo aos descendentes da espécie humana.

De acordo com os autores, praticamente todo pensamento importante acontece fora do que a consciência pode alcançar, a consciência pode vislumbrar somente alguns poucos vestígios do que a mente é feita. Muitos feitos mentais que classificamos como impressionantes, são triviais para atividade cognitiva constantemente executada no interior de nosso organismo.

Por partirem de uma concepção de mente "corporificada", os autores defendem a tese da onipresença do blend na atividade intelectual. Assim, tal operação se faz presente não somente na atividade intelectual criativa, mas também na atividade intelectual rotineira, que acontece a todo o momento e em todos os tipos de realizações do viver.

É possível perceber que a operação de integração de espaços mentais é imprescindível à elaboração dos níveis de integração propostos pela Semiótica Cognitiva. As duas teorias - a da Integração Conceptual e a da Arquitetura Mental - se aproximam na medida em que relacionam a produção de significado a operações biofisiológicas do ser humano, mas se afastam na medida em que a abordagem brandtiana extrapola os limites da teoria de Integração, e propõe a criação de um espaço-base no qual o ser humano só produz sentido na relação com o outro.

A significação produzida por nós de maneira natural (eu) compõe um processo cognitivo intenso e constante, produzido por nosso mecanismo biológico, nas (re) incidências das relações estabelecidas com 
as outras pessoas (tu), com o/no mundo da vida (aqui/agora). Tais entendimentos só nos são possíveis porque o mundo existe a partir de nossa capacidade de criação e significação do mundo, das coisas e das interações sociais.

Nada nos é dado por um mundo preexistente, tudo que temos é a possibilidade que nossa mente corporificada nos dá de construirmos o mundo da vida virtualmente, por meio de atualizações das relações possíveis com o meio o qual integramos e ao qual nos integramos.

Com o intuito de não perder os aspectos abordados durante a seção e resumi-la, elenco alguns tópicos abordados no decorrer de sua escrita: i) o campo da Semiótica Cognitiva nos possibilita compreender os processos de comunicação e interação através da arquitetura mental geradora de significado da mente humana; ii) a arquitetura mental da significação pode ser compreendida como forma de mapear os possíveis estágios de significação nos mais diferentes contextos sociocognitivos; iii) no processo de produção do sentido, está implicada uma operação cognitiva básica, a integração conceptual; iv) a integração conceptual configura-se como integração de espaços mentais que formam um blending; v) o blending é uma operação cognitiva básica, amplamente aplicável e naturalmente efetuada pelo ser humano; vi) a integração conceptual é imprescindível à elaboração de níveis mentais de integração propostos pela Semiótica Cognitiva; vii) esta última extrapola os limites da primeira no sentido de que propõe a criação de um espaço-base no qual o ser humano só produz sentido em relação com o outro.

Com base no que foi discutido até este momento, é coerente afirmar que o ser humano, como ser de significação que é, é ca- paz de produzir sentido ao pensar metaforicamente. 0 pensamento metafórico é a forma elementar de organização da atividade intelectual humana, assim, metaforicamente, o ser humano produz sentido para viver. 0 processo de metaforização, por meio da linguagem, que é uma disposição ontogenética dos seres humanos, longe de ser algo especial e noticiável, é algo convencional, ordinário, corriqueiro na vida humana.

Frente aos fundamentos ora apresentados, fica claro que, à luz da Semiótica Cognitiva, o processo de metaforização, possível de ser rastreado em elementos discursivocognitivos, como uma forma pela qual nós seres humanos concebemos nossas capacidades corpóreo-cognitivas. Por meio da produção de metáforas, somos capazes de expressar simbolicamente e significar coletivamente experiências humanas mais fisiologicamente dependentes, certos qualia e certas experiências afetivas. Por isso, é plausível afirmar que o processo de metaforização é constitutivo do processo de produção de sentido e que, para além de uma figura de linguagem, a metáfora é uma operação cognitiva e deve ser compreendida como uma capacidade humana de traduzir fenômenos abstratos em termos de experiências corporais mais concretas.

\section{bases fenomenológicas para a pesquisa em semiótica cognitiva}

Acredito que utilizar bases metodológicas de ordem fenomenológica ajude a selecionar o material de estudo a partir de uma experiência empírica com os possíveis objetos de pesquisa. Primar por uma metodologia, prioritariamente, experiencial e perceptiva é um desafio que o pesquisador cognitivista deve assumir, em busca de descrever e analisar a experiência humana com objetos dis- 
cursivos, estéticos, culturais, populares, tecnológicos etc. à procura de possíveis marcas emergentes dos processos subjacentes à construção de sentido.

Assim, a postura de compreender que nada existe antes da experimentação, nos permite valorizar e priorizar a experiência do ser humano consigo mesmo, com o outro e com o mundo que constrói no momento de sua experienciação. Para isso, admitir como importante a assunção da premissa de que o mundo físico e social é o meio natural do ser humano e o campo natural de todas as nossas experienciações, experimentações, percepções, pensamentos e, portanto, produção de sentido. Fica evidente, então, que é coerente a afiliação a uma corrente de pensamento filosófica segundo a qual é pouco possível a existência de uma parcela unicamente interior ao homem, já que ele se constitui e é constituído no mundo que conhece, ou seja, não é possível particionar o ser humano em interior e exterior, em corpo biológico e meio social. (MERLEAU-PONTY, 1999).

Entender o mundo a partir de conceitos fenomenológicos e utilizar tais princípios como base de constituição de um trabalho de pesquisa, é compreender que não há um ser humano prévio à experiência do mundo e à concepção da própria vida. Para isso, é importante estabelecer bases de investigação que privilegiem a atividade humana como ponto central do problema a ser verificado. Neste contexto, uma fundamentação metodológica ancorada na fenomenologia, permite ao pesquisador assumir, como premissa básica, as operações cognitivas como constitutivos basilares de nossas interações discursivas.

É claro que, adotando uma perspectiva centrada na experiência humana, é preciso reconhecer os limites de uma pesquisa científica quanto à intrínseca diferenciação en- tre: a experiência de fato genuína, na construção de sentido, a partir do contato com um objeto estético-cultural; e a experiência, interpretada a partir de princípios teóricos, metodológicos e analíticos, a ser captada num trabalho acadêmico. Sobre essa "limitação" do campo científico, Merleau-Ponty (1999) afirma:

Todo o universo da ciência é construído sobre o mundo vivido, e se queremos pensar a própria ciência com rigor, apreciar exatamente seu sentido e seu alcance, precisamos primeiramente despertar essa experiência do mundo da qual ela é a expressão segunda. A ciência não tem e não terá jamais o mesmo sentido de ser que o mundo percebido, pela simples razão de que ela é uma determinação ou uma explicação dele. (MERLEAU -PONTY, 1999, p. 3).

Os propósitos científicos de investigação, análise e explicação fazem com que a constituição do mundo da vida não componha, substancialmente, o objeto de uma pesquisa, sendo essa, então, ressignificada a partir de objetivos que fogem ao propósito primeiro da produção de sentido por parte do ser humano, que é a auto-organização para viver. Nesse sentido, para compreender e explicar a experiência do ser humano do/ no mundo, podemos explicar o que torna tal experiência possível sem, no entanto, poder, por conta dos limites interpostos pela investigação, abarcar aquilo que ela realmente é. Reconhecidos os limites de uma pesquisa de orientação experiencial, é preciso dizer que em trabalhos focados em processos humanos bases metodológicas focadas na experiência do ser frente à vida, ao mundo e às suas produções se fazem procedentes.

\section{Conclusão}

Neste artigo, pretendi demonstrar, por meio de fundamentos teóricos da Semiótica Cog- 
nitiva, bases referenciais e metodológicas que possibilitam pesquisas acerca da produção de sentido humana por meio da linguagem. Para isso, percorri brevemente uma das principais correntes cognitivistas contemporâneas, a perspectiva da Universidade de Aarhus, além de elencar princípios da Integração Conceptual e também do campo da Fenomenologia. Meu objetivo maior é ajudar pesquisadores que tenham interesse neste campo, trazendo alguns conceitos e referências iniciais importantes para os estudos em Semiótica Cognitiva.

É preciso frisar que trabalhar em uma perspectiva teórica relativamente nova, que realoca o ser humano como o centro da investigação, exige esforço, concentração e uma atividade manual e intelectual de todo investigador no âmbito da Semiótica. Exatamente por serem pesquisas desafiantes, muitos se sentem estimulados a se debruçarem cada vez mais sobre elas, é para esse público que dedico esta escrita.

\section{Referências}

BRAIT. B. Bakhtin: outros conceitos-chave. Organizado por: Beth Brait. São Paulo: Contexto, 2010.

BRANDT, Peer A. Spaces, Domains, and Meanings. Bern: Peter Lang Verlag European Academic Publishers, no 4, 2004.

BRANDT, Peer A. The mental architecture of meaning. A view from cognitive semiotics. Revista digital de tecnologias cognitivas. 2010, n.4, p. 25-36, julho 2010.
BRANDT, Peer A. Thinking and language. A view from cognitive semio-linguistics. 2009. Em: https://www.researchgate.net/publication/226155542_Thinking_and_Language Acesso em: 21 jul. 2019 às 16:21.

CAVALCANTE, Sandra. SOUZA, André L. Linguística Cognitiva: uma breve introdução in: Linguagem e Cognição: diferentes perspectivas, de cada lugar um outro olhar / Organização: Arabie Bezri Hermont, Rosana Silva do Espírito Santo, Sandra Maria Silva Cavalcante. Belo Horizonte: Ed. Puc Minas, 2010.

FAUCONNIER, Gilles. TURNER, Mark. The way we think: conceptual blending and mind's hidden complexities. New York: Basic Books, 2002.

MARCUZZO, Patrícia. Diálogo inconcluso: os conceitos de dialogismo e polifonia na obra de Mikhail Bakhtin. Cadernos do IL, Porto Alegre, no 36, jun. 2008. Disponível em: http:// www.seer.ufrgs.br/cadernosdoil/ Acesso em: 10 fev. 2020.

MERLEAU-PONTY, Maurice. Fenomenologia da percepção. $2^{\underline{a}}$ ed. São Paulo: Martins Fontes, 1999

OAKLEY, Todd; HOUGARD, Anders. Mental spaces in discourse and interaction. Philadelphia: John Benjamins North America, 2008.

VOLOCHINOV, V. N.; Marxismo e filosofia da linguagem: problemas fundamentais do método sociológico da linguagem. São Paulo: Editora 34, 2018.

ZAVALA, Iris. 0 que estava presente desde a origem. In: BRAIT, Beth (Org). Bakhtin, dialogismo e polifonia. São Paulo: Contexto, 2009, p.151-166.

Recebido em: 15/05/2020 Aceito em: 15/06/2020 